\title{
The stream of desire and Jung's concept of psychic energy
}

\author{
Raya A. Jones
}

\begin{abstract}
Whether energy is God or God is energy concerns me very little, for how, in any case, can I know such things? But to give appropriate psychological explanations — this I must be able to do. (C. G. Jung) ${ }^{1}$
\end{abstract}

It is a remarkable quality of Jung's legacy that it appeals across diverse disciplines, but I put the above statement upfront as a reminder that as a therapist Jung was concerned first and foremost with explaining the kind of phenomena that clinicians confront in their patients. If a concept of energy or libido does the job, so to speak, that's more important than whether the concept is metaphysically sound or not. Nevertheless, Jung did attempt to articulate a cogent theory of what precisely psychic energy might be. His theorizing about psychic energy took off in the 1912 monograph, Psychology of the Unconscious which four decades later was lightly revised as Symbols of Transformation. ${ }^{2}$ Seeking the appropriate psychological explanation for patients' symptoms, he argued that the Freudian notion of libido as sexual energy is inapplicable to dementia praecox since the illness is associated with the generation of a fantasy world rather than with heightened sexuality. This argument set him on a line of

\footnotetext{
${ }^{1}$ C.G. Jung, Collected Works, ed. Sir H. Read, M. Fordham, G. Adler, and W. McGuire, 20 vols,
} London: Routledge \& Kegan Paul, 1953-1983, vol. 8, The Structure and Dynamics of the Psyche, $\S 678$.

${ }^{2}$ C.G. Jung, Psychology of the Unconscious, London: Kegan Paul, Trench, Turner \& Co. 1919; revised Symbols of Transformation [Collected Works, vol. 5]. 
theorizing that has culminated in the theory of the archetypes. The assumption of psychic energy runs throughout Jung's psychology in general. His differentiation between introverts and extroverts is based on it, and it is central for his theory of the autonomous complexes and how complexes form around archetypal nuclei (summarised in Jung's 1928 essay On Psychic Energy). ${ }^{3}$

Jung's attempt to clarify a concept of psychic energy was one of several theories of mental energy that were bandied about in the first half of the last century, not only in depth psychology but also in general psychology. Elsewhere I have compared Jung's revision of libido with the concept of energy underpinning the field theory that the gestalt psychologist Kurt Lewin articulated in the 1930s. ${ }^{4}$ In The Energies of Men, first published in 1932, William McDougall regarded a concept of energy as indispensable: 'In view of the purposive nature of human activity, [we] must postulate some energy which conforms to laws not wholly identical with the laws of energy stated by the physical sciences. ${ }^{5}$ Contesting the terminology of 'psychic' energy, he proposed a concept of 'hormic' energy (defined as an urge or impulse towards a goal) as a means to forging connections between processes of the body and processes of the mind within a unified science of psychology — a science that in McDougall's view had no room for psychoanalytical doctrines. And then, as if suddenly midcentury, the whole discourse of energies vanished. Concepts of mental energy have become obsolete in the wake of the cognitive revolution.

A roughly parallel trajectory can be tracked in the history of the idea within analytical psychology. By the 1980s, Samuels queried whether analytical psychology needs a concept

\footnotetext{
${ }^{3}$ C.G. Jung, 'On Psychic Energy', in Collected Works, vol. 8, §1-§130.

${ }^{4}$ R.A. Jones, 'Psychological value and symbol formation', Theory \& Psychology, 2001, vol. 11, 23354; and R.A. Jones, Jung, Psychology, Postmodernity, London: Routledge, 2007.

${ }^{5}$ W. McDougall, The Energies of Men, 8th edn, London: Methuen 1950, p. 10.
} 
of energy, though he conceded that 'the notion of energy, even if taken nowadays purely as a metaphor, helps to explain differences in perception. ${ }^{6}$ However, in contradistinction to the academic debates about mental energy early on, Jung's concept of psychic energy has seldom been examined or debated in Jungian circles despite its original centrality. First published in 1948, Esther Harding's book, Psychic Energy — with a Preface by Jung — is a tour-de-force of symbolism and their signification; ${ }^{7}$ but it does not contain any definition of psychic energy. A similar observation could be made about John Beebe's recent book, Energies and Patterns in Psychological Type. ${ }^{8}$ Beebe uses the word 'energy' liberally but in a commonsense way, as an everyday concept that requires no explanation. His theoretical investment is in the concept of psychological types. 'Psychic energy' continues to be acknowledged in textbooks as something that $\mathrm{Jung} \mathrm{said}^{9}$ and is the topic of scholarly publications that attempt to clarify what Jung meant and to locate his idea historically, ${ }^{10}$ but at best we can offer fresh insights into what he was saying and why he was saying it. As a scientific or quasi-scientific explanation, this construct has lost its vitality.

This chapter revisits Jung's concept from another direction. Instead of examining its place in the intellectual history of modern psychology, I want to tease out an ancient image

${ }^{6}$ A. Samuels, Jung and the Post-Jungians, London: Routledge \& Kegan Paul, 1985, p. 114.

${ }^{7}$ E. Harding, Psychic Energy, 2nd edn, Princeton, NJ: Princeton University Press, 1963.

${ }^{8}$ J. Beebe, Energies and Patterns in Psychological Type, London: Routledge, 2016.

${ }^{9}$ See, for example, e.g., M. Stein, Jung's Map of the Soul, Chicago, IL: Open Court, 1998.

${ }^{10}$ See, for example, C. Kerslake, 'Rebirth through incest: on Deleuze's early Jungianism', Angelaki, 2004, vol. 9, 135-156; S. Shamdasani, Jung and the Making of Modern Psychology,. Cambridge:

Cambridge University Press, 2003; D.I. Tresan, 'This new science of ours: a more or less systematic history of consciousness: Part 1', Journal of Analytical Psychology, 2004, vol. 49, 193-216; and my own works (op. cit.). 
— the stream of desire — that Jung both inherits and resists when he strives to improve upon the Freudian concept: 'By libido I mean psychic energy. Psychic energy is the intensity of a psychic process, its psychological value. [...] Neither do I understand libido as a psychic force, a misconception that has led many critics astray,' says Jung. ${ }^{11}$ We should not be misled by the linearity of terminological succession. Jung's psychological value is not a synonym for Freud's libido but its antonym, as will be seen.

\section{The ancient stream}

There is an obvious association, a kind of continuity, between the Freudian libido and the stream-of-desire image. Dictionaries tell us that the word libido originates in the Latin for desire or lust; and there is an etymological connection to the English word love. The imaginative association between a stream and desire is explicit in the Dammapada, where it carries a moral message: 'When the thirty-six streams of desire that run towards pleasure are strong, their powerful waves carry away that man'; 'Go beyond the stream ... go with all your soul: leave desires behind'. ${ }^{12}$ In historical parallel, in Republic Plato deploys an almost identical image: 'anyone whose predilection tends strongly in a single direction has correspondingly less desire for other things, like a stream whose flow has been diverted into another channel. ${ }^{13}$ The same imagery flows on into psychoanalytical theory. Freud speaks of

\footnotetext{
${ }^{11}$ Jung, Collected Works, vol. 6, Psychological Types, $\$ 778$.

${ }^{12}$ J. Mascaró, The Dhammapada, Harmondsworth: Penguin, 1973, §339, §383.

${ }^{13}$ Plato, Republic, 485d; in Plato, Republic, trans. R. Waterfield, Oxford: Oxford University Press, $1993, \S 485 \mathrm{~d} / \mathrm{p} .205$
} 
'a collateral filling of subsidiary channels when the main current of the instinctual stream has been blocked by "repression". ${ }^{14}$ Likewise in Jung's works we find assertions such as:

Just as the libido may be compared to a steady stream pouring its waters into the world of reality, so a resistance [to sexual desire] [...] resembles, not a rock that juts up from the river-bed and causes the stream to flow around it, but a flowing back towards the source. Part of the psyche really wants the external object, but another part of it strives back to the subjective world, where the airy and lightly build palaces of fantasy beckon. ${ }^{15}$

In the 1928 essay on psychic energy and elsewhere Jung devoted considerable space to libidinal flow — he talks of regression, progression, and canalisation and transformation which he offers as an explanation for a variety of response patterns, including fantasies.

Neither Freud nor Jung mentioned Plato's stream analogy apropos of libido (to my knowledge). Instead, in the 1920 Preface to the fourth edition of 'Three Essays on the Theory of Sexuality', Freud cites a 1915 article that compared his own theory with Plato's Eros, and reflects 'how closely the enlarged sexuality of psycho-analysis coincides with the Eros of the divine Plato'. ${ }^{16}$ Ever since, some scholars seem inclined to fuse Plato's hydraulic metaphor with Eros with and to discuss both the Republic and the Symposium as postulating a primordial energy source. According to Jon Moline,

\footnotetext{
${ }^{14}$ S. Freud, 'Three Essays on the Theory of Sexuality', in On Sexuality: Three Essays on Sexuality and Other Works, ed. A. Richards, The Pelican Freud Library Vol. 7 (pp. 33-170). Harmondsworth, Penguin (p. 156)

15 Jung, Collected Works, vol. 6, Psychological Types, §253.

${ }^{16}$ Freud, 'Three Essays on the Theory of Sexuality', p. 43.
} 
The parts of the psyche are like channels or tubes into which the flow of a single stream is divided. The total flowage is constant, so that what goes into one tube or channel is lost to the others ... Both the Republic and the Symposium suggest that this single source is eros, a primordial energy source powering not simply the stereotypically erotic activities, but all human activities whatsoever. ${ }^{17}$

Similarly, Henry Teloh took the stream analogy in the Republic as pivotal for understanding Plato's conception of the soul as psychic energy. ${ }^{18}$ Commenting on Teloh's paper, M.L. Osborne contends that such interpretation is not borne out by Plato's argument in the same context. ${ }^{19}$ I concur with Osborne.

Arguably, it is Freud who has made it possible to link Plato's stream analogy and some concept of Eros (Plato in fact presents several concepts through the various speakers in the Symposium). It is Freud - not Plato - who upheld Eros, equated with sexual excitation, as universally the strongest motivating force. This claim seemed justified in view of how evolution, human biology, and energy were understood circa 1900, but it was not possible to make in Plato's time. It seems anachronistic to attribute to Plato an understanding of the Greek love-god as psychic energy. The ancients did not have the mechanistic concept of energy that underpins Freudian thinking, and by extension empowers Jung's departure from

${ }^{17}$ J. Moline, Plato's Theory of Understanding, Madison, WI: University of Wisconsin Press, 1981, pp. 77-78.

${ }^{18}$ H. Teloh, 'Human nature, psychic energy, and self-actualization in Plato's Republic', The Southern Journal of Philosophy, 1976, vol. 14, 345-358.

${ }^{19}$ M.L. Osborne, 'On the image of the soul as a stream in Plato's Republic', The Southern Journal of Philosophy, 1976, vol. 14, 359-363. 
Freud. The pitfalls of reading Plato through a Freudian lens may serve as a cautionary tale for seeking continuities between Jung and the classics.

\section{Bridging Jung and ancient thought}

One obvious way to bridge analytical psychology and the study of ancient thought is to approach the topic from the standpoint of Jung scholarship; that is, 'Jung' being one's subject matter. It is possible to scour the Collected Works for citations and to analyse how Jung brings those to bear on his theory building; or to interrogate the Jungian corpus for 'influences', whether acknowledged or not. As Henri Bergson averred, 'even today, we shall philosophize in the manner of the Greeks, we shall rediscover, without needing to know them, such and such of their general conclusions. ${ }^{20}$ However, this strategy might not take us very far regarding the topic of psychic energy.

In the 1928 essay, ${ }^{21}$ Jung lists the following in a single sentence — and in this order - as concepts that are similar to his own but only of limited overlap:

- Schopenhauer's Will

- Aristotle's horme

- Plato's Eros

- Empedocles' 'love and hate of the elements'

- Bergson's élan vital.

The order of the list perhaps represents a descending order of similarity. In Symbols of Transformation Jung quotes Schopenhauer at length by way of supporting why he himself

\footnotetext{
${ }^{20}$ H. Bergson, Creative Evolution, Mineeola, NY: Dover, 1911, p. 316.

${ }^{21}$ Jung, Collected Works, vol. 8, The Structure and Dynamics of the Psyche, §55.
} 
insists that energy is not a force. ${ }^{22}$ Schopenhauer distinguished Will from its phenomenal appearances, reasoning that the abstract concept of force is derived from sense perception. ${ }^{23}$ But unless we delve into Schopenhauer's system of thought, this comparison can backfire, so to speak. Schopenhauer's concept does not imply freedom to control one's behaviour (o willpower). Bergson is at the bottom of Jung's list perhaps because Jung repeatedly fended off his own critics who accused him of vitalism, hence he was not keen to associate his concept with élan vital. In the present context, the main point is that the Greeks are merely sandwiched between the two modern philosophers.

The link that Jung ultimately makes — or the bridge he builds — is across modernity and so-called 'primitive' mentality. A few paragraphs before the aforementioned list he states that 'energy is an immediate, a priori, intuitive idea,' concludes in a related footnote that 'therefore the idea of it is as old as humanity' and proceeds to discuss the Melanesian concept of mana as reported by anthropologists of the era. ${ }^{24}$ The final part of 'On Psychic Energy' is dedicated to examples of equivalent concepts among tribal societies all over the world.

A second strategy to bridge Jung and the ancients is to take the classics as our subject matter and revisit them through a Jungian lens, though here lies the epistemological risk demonstrated in the case of reading Plato through Freud. If we take 'ancient thought' to mean also traditions from the Far East and what Jung called 'primitive' mentality, we can see a version of this strategy in his own work - the way he revisits those in order to demonstrate manifestations of the psychological principles he has already postulated.

The final strategy is where the troll under the bridge comes into the picture, trying to stop us from crossing. Asking what Jung and the ancients have and do not have in common

\footnotetext{
${ }^{22}$ Jung, Collected Works, vol. 5, Symbols of Transformation, §197.

${ }^{23}$ A. Schopenhauer, The World as Will and Idea, London: Kegan Paul, 1922.

${ }^{24}$ Jung, Collected Works, vol. 8, §52.
} 
brings to the fore discontinuities and contingent tensions as well as similarities or continuities of thought. Jung's theorising about psychic energy, especially in the 1928 essay, focalises a few sites of tension that characterise modern psychology in general. One site, which he identifies himself, is comprised of tensions between causal-mechanistic and functional explanations in psychology (more about this in the next section); and, placed in the same site, tensions between qualitative and quantitative concepts. Another site is implicated by Jung's distinction between 'pure' and the 'concrete' concepts of psychic energy. It focalises tensions associated with the traditional debate of whether psychology is a science or an art. Jung presents his pure/concrete distinction as a matter of convenience: strictly speaking the pure concept does not permit us to think of energy as if it were a causal factor; but when we wish to apply it, especially in clinical practice, it is convenient to speak in concrete terms such as saying that someone's fantasies or emotional reactions and so forth are caused by libidinal regression or progression. Jung moves at ease from one mode to the other, but this makes his 1928 essay on the whole appear as inconsistent.

A third site of tensions arises from Jung's claim that the intuitive notion of energy is as old as humanity itself. His case for revising the libido concept in the 1912 monograph involved lengthy and quite dense account of myths of the sun god, fire, and related etymologies, which was slightly streamlined in the 1952 revision. He relates these to bodily sensations of rhythm. The final section of the 1928 essay lists at length examples of 'primitive' concepts of power, typically attributed to spirits. Comparable views can be found also in Eastern mysticism — notions of cosmic energy that flows through mind and body and everything. Indeed, since about the 1960s Jung's exposition of psychic energy has become eclipsed by popularised extrapolations from Oriental mysticism. Jung himself seems to orient us in that direction in his accounts of intuitive precursors of the modern concept of energy, and indirectly to reinforce the orientation with the unus mundus premise he extrapolated from 
medieval alchemy. Ultimately the invocation of those (or any) cosmologies is incommensurable with his definition of energy as psychological value - a concept that refers to the meaning that something has for someone. Remember that whether energy is God or God is energy concerned him very little. In terms of a psychological explanation, the tensions that come to light at this juncture gravitate towards the ancient metaphysical problem of universals. It is a problematic throughout modern psychology, but in the context of Jungianism it manifests in a tendency to abstract psychological universals, such as archetypes, from an aggregate of particular instances (myths, fairytales, patients' dreams, etc.) that at best share a family resemblance; and then to concretise the abstract construct as if it were a causal factor, saying that these instances occur because of the archetypal configuration.

\section{Enter the machine}

What Jung and the ancients do not have in common can be conveyed, again, with the aid of Bergson, namely that 'ancient science applied to concepts, while modern science seeks laws. ${ }^{25}$ Unlike the Dhammapada, which instructs how to live virtuously, both Freud and Jung inform us why we live as we do, vice and virtue alike. In modernity the stream analogy merges into a mechanistic metaphor of energy as a motivating force. The stream becomes steam power. Concepts of mental energy, libido and so forth, were invented so as to account for how the psyche works. It is (or was) commonly assumed that some form of energy powers the intrapsychic machinery in accordance with natural laws; and those laws have to

\footnotetext{
${ }^{25}$ Bergson, Creative Evolution, p. 333.
} 
be discovered and articulated. Consequently, debates during the first half of the last century centred on what is the appropriate conceptualisation.

Jung entered the intellectual arena with a contention that previous definitions (not only Freud's) were mistaken because they confused energy with a substance:

The idea of energy is not that of substance moved in space, it is a concept abstracted from relations of movement. The concept, therefore, is founded not on the substances themselves but on their relations, whereas the moving substance itself is the basis of the mechanistic view. ${ }^{26}$

Jung thus pitches two approaches against each other. According to the causal-mechanistic view (which he contests), energy is synonymous with a force or a drive. It is conceptualised as substance-like, a 'thing' that causes movements in the psyche. We may imagine, for instance, the water that makes the watermill turn (my metaphor). This posits the existence of energy as a precondition for psychological phenomena, just as water must exist before the watermill can do its work. In opposition to the causal-mechanistic view, Jung articulates what he calls the 'energic' or interchangeably the 'final' view, which removes the arrow of causality. It puts the phenomena first, arguing that intrapsychic movements (which already exist) can be expressed in terms of an energy quantum. By analogy, we are looking at the energy that the watermill produces by virtue of its operation (while the causal-mechanistic position confuses the force of the flowing water for the energy that the watermill produces). The word 'final' has connotations of teleological, which Jung himself contested. The

\footnotetext{
${ }^{26}$ Jung, Collected Works, vol. 8, On the Nature and Dynamics of the Psyche, §3.
} 
epistemological position that he endorses is best called a functional approach. ${ }^{27}$ Such approach identifies how something functions within the whole of the person's psychological processes. It does not necessarily oppose the machine metaphor, for we may compare it to describing the function of a $\operatorname{cog}$ in a machine, i.e. how this element is necessary for the machine's capacity for doing its work (to paraphrase the commonplace definition of energy in physics).

The energic/final/functional approach does not eliminate the epistemological necessity of explaining how movements in the psyche are caused. Jung does not reject causal explanations per se, but objects to regarding energy as a causal factor. He brings together causality and functionality, for instance, when attributing the formation of symbols to a situation where a conflict between two mutually incompatible subjective states generates psychological tension that is eventually transcended through the formation of a new symbol:

The confrontation of the two positions generates a tension charged with energy and creates a living thing, a third thing [...] a movement out of the suspension between opposites, a living birth that leads to a new level of being, a new situation. ${ }^{28}$

The new symbol constitutes a new object - not merely a token for something repressed (contra Freud), but something with its own meaning or aura of meaningfulness. Its energy quantum is its psychological value, evident in the intensity and direction of affect, for 'psychological value [...] does not imply an assignment of value, whether moral, aesthetic, or

${ }^{27}$ See Jones, 'Psychological value and symbol formation', p. $239 \mathrm{ff}$.

${ }^{28}$ Jung, Collected Works, vol. 8, On the Nature and Dynamics of the Psyche, §189. 
intellectual; the psychological value is already implicit in its determining power, which expresses itself in definite psychic effects'. ${ }^{29}$

\section{Conclusion}

We cannot step into the same stream twice. As seen, some scholars who step into Plato's stream analogy after Freud see reflections of Eros there and are inclined to redefine Plato's Eros as a primordial energy source powering human activities. How should we step into the stream after Jung? His reformulation of the libido does not write off the stream analogy, but alters its application. Jung's 1928 essay labours towards a concept of dynamism as an abstract property of the psyche in the sense that 'flow' is a property of a stream. With Freud we would see libido like seeing the 'behaviour' of water when standing outside a stream: libido is channelled, blocked, diverted, or dispersed unequally across various channels. Following Jung, we may imagine ourselves like a grain of sand carried by its torrent, experiencing it from within, and should ask what it 'feels like' to be caught in the turbulence.

Jung insists that his own task, what he must be able to do, is to give an appropriate psychological explanation. However, explanatory constructs in psychology come and go alike intellectual fashions though every new fashion is heralded as a scientific paradigm shift and therefore as progress. Walter Benjamin has given a vivid characterisation of the concept of progress in his meditation on a painting by Klee ('Angelus Novus'). Describing it as showing an angel 'looking as though he is about to move away from something he is fixedly contemplating,' Benjamin mused,

\footnotetext{
29 Jung, Collected Works, vol. 6, Psychological Types, $\$ 778$.
} 
But a storm is blowing in from Paradise; it has got caught in his wings with such a violence that the angel can no longer close them. The storm irresistibly propels him into the future to which his back is turned, while the pile of debris before him grows skyward. This storm is what we call progress. ${ }^{30}$

In a way, Jung is like this angel when theorizing about psychic energy. He sees the debris of previous concepts, which he deconstructs and finds deficient, and cannot see the future - the cognitive revolution in psychology of the second half of the 20th century, which has rendered concepts of mental energy obsolete and has redefined psychological explanations based on such concepts as inappropriate. However, Jung is fixated on the past not only like Benjamin's angel of history but also in that he looks to the very far distance, our evolutionary past, and finds the intuitive notion of energy as old as humanity itself.

Jung neither endorsed nor challenged the primitive and ancient cosmologies he identified as precursors of the modern 'energy' construct. Instead, he asks why human beings have these notions at all, what psychological function these might serve. Jung ends the essay on psychic energy thus:

The most universal incidence of the primitive concept of energy is a clear expression of the fact that even at early levels of human consciousness man felt the need to represent the sensed dynamism of psychic events in a concrete way. If, therefore, in our psychology we lay stress on the energic point of view, this is in accord with the psychic facts which have been graven on the mind of man since primordial times. ${ }^{31}$

\footnotetext{
${ }^{30}$ W. Benjamin, Selected Writings Vol. 4: 1938-1940, eds. H. Eiland and M. W. Jennings, Cambridge: Harvard University Press, 2003, p. 392-3.

${ }^{31}$ Jung, Collected Works, vol. 8, On the Nature and Dynamics of the Psyche, §130.
} 
Rhetorically this 'final word' performs an interesting manoeuvre that undermines the thrust of the first part of the same essay. The essay began with an intense effort to establish the correct logical way of conceptualising psychic energy by eliminating rival theories as mistaken. Jung even contrives to specify psychic parallels of the laws of thermodynamics (which arguably does not really 'work'). But he ends up persuading us that in any permutation such notions capture something that is intuited from bodily lived experience. In other words, the scientific concept is just one of many historically contingent manifestations of something that is timeless within our psyche. 